\title{
KESTABILAN DINDING PENAHAN BATU KALI PADA TANAH LUNAK
}

\author{
WidayatAmariansah $^{1}$, Ummi Chasanah $^{2}$, Lintang Enggartiasto $^{3}$ \\ ${ }^{1,2}$ Prodi Teknik Sipil Universitas Pandanaran \\ Jalan Banjarsari Barat no.1, Pedalangan, Banyumanik, Semarang \\ ${ }^{3}$ Mahasiswa Magister TeknikSipil Fakultas Teknik Unissula \\ Jalan Raya Kaligawe km.4, Semarang \\ Email :awidayat1962@gmail.com
}

\begin{abstract}
ABSTRAK
Lapisan tanah lunak di daerah pantai Tambak Lorok Semarang mengalami penurunan $4 \mathrm{~cm}$ per tahun dan kenaikan muka air laut $1 \mathrm{~cm}$ per tahun membutuhkan penimbunan tanah ketika akan membuat bangunan baru di atasnya. Timbunan tanah ini memerlukan dinding penahan tanah atau talud dari pasangan batu kali agar timbunan tersebut tidak longsor sekaligus sebagai batas kepemilikan lahan. Talud yang dibuat harus stabil terhadap gaya vertikal, lateral, momen, daya dukung ijin tanah, gaya dalam dan penurunan tanah lunak yang bakal terjadi. Pada kondisi tertentu penambahan tiang pancang kayu dapat menambah kestabilan talud terutama terhadap efek penurunan struktur talud.
\end{abstract}

Kata kunci :Kestabilan, dinding penahan, tanah lunak

\section{ABSTRACT}

Tambak Lorok alluvial area in Semarang have thick soft soil result in land subsidence4 $\mathrm{cm}$ each year and increasing sea water level $1 \mathrm{~cm}$ each year. This area must be reclamated before build a new building. The reclamation need retaining wall from stone masonry to protect the barrow from landslide at once as border owned area. The retaining wall must be safe and stable to resist vertical force, uplift force, lateral force, moment, allowable bearing capacity, stone masonry inner force and setllement. In special case, wooden pile can increase stability of retaining wall especially in settlement effect.

Keywords: stability, retaining wall, soft soil

\section{PENDAHULUAN}

Kondisi tanah lunak di daerah pantai seperti kawasan Tambak Lorok Semarang yang cenderung mengalami penurunan $4 \mathrm{~cm}$ per tahun dan kenaikan muka air laut $1 \mathrm{~cm}$ per tahun (LPPM Undip-PLN Enjiniring, 2017), membutuhkan penimbunan tanah ketika akan membuat bangunan baru di atasnya. Penimbunan ini bertujuan untuk mendapatkan permukaan tanah bangunan yang lebih padat, rata dan bebas dari genangan muka air laut atau rob sehingga utilitas yang dibangun dapat berfungsi optimal. Timbunan tanah ini memerlukan dinding penahan tanah atau talud dari pasangan batu kali atau beton bertulang agar timbunan tersebut tidak longsor sekaligus sebagai batas kepemilikan lahan. Talud yang dibuat harus stabil terhadap gaya vertikal, lateral, momen, daya dukung ijin tanah dan penurunan tanah lunak yang bakal terjadi.

Dinding penahan tanah (DPT) atau talud merupakan bangunan permanen dari pasangan batu kali yang berfungsi memisahkan dan menahan kestabilan dua bidang tanah yang mempunyai beda tinggi (Widayat, 2015). Gaya yang bekerja terdiri dari gaya vertikal, lateral danmomen. Gaya vertikal tekan terdiri atas berat sendiri DPT, sedangkan gaya vertikal tarik/angkat (uplift) berasal dari tekanan air tanah. Gaya lateral arah $\mathrm{x}$ maupun y dapat berupa tekanan air tanah, tekanan tanah aktif akibat sejumlah massa tanah yang ditahan di belakang DPT, akibat gaya gempa, akibat beban hidup merata yang bekerja di atas muka tanah seperti beban kendaraan, beban crane, beban mesin, beban bangunan di sekitarnya dan sebagainya. Selain itu ada gaya lateral lain yang sering diperhitungkan yaitu gaya dorong tanah di atas talud yang berpotensi longsor, jika beda tinggi tanah yang ditahan talud cukup tinggi sehingga garis lingkaran kritis longsor melewati bawah pondasi DPT. Dalam kondisi demikian maka pondasi talud diperdalam dan diperbesar bahkan jika perlu diperkuat tiang pancang. Momen pada DPT 
berasal dari interaksi gaya vertikal dan lateral terhadap titik guling talud yang masingmasing berfungsi menahan dan menggulingkan DPT.

SNI 8640-2017 mensyaratkan faktor keamanan untuk kestabilan DPT terhadap daya dukung ijin tanah adalah 3, gaya angkat dan momen guling adalah 2, sedangkan gaya geser adalah 1,50. Kestabilan DPT juga wajib ditinjau terhadap penurunan segera dan konsolidasi ketika berdiri di atas lapisan tanah lunak, dan runtuhnya konstruksi pasangan batu akibat tegangan yang berasal gaya dalam yang bekerja padanya baik berupa tegangan tekan, tarik serta geser.SNI 8640-2017 mensyaratkan penurunan total yang diijinkan $<15 \mathrm{~cm}$, sedangkan Skempton dan MacDonald (1955) memberi batasan maksimum 4-10 cm, Bouwless (1993) mengisyaratkan 2,50-3 cm, Suyono dan Nakazawa (1984) merekomendasikan 2,50 $\mathrm{cm}$ dan Hardiyatmo (2006) menganjurkan $2,50 \mathrm{~cm}$. Berhubung DPT terletak pada lapisan tanah lunak setebal 30 m (Lab. Mektan Undip, 2017) maka resiko penurunan tanah menjadi perhatian utama yang bisa diatasi antara lain dengan penambahan tiang pancang kayu, perkuatan tanah dasar dengan lantai kerja beton tumbuk dan lapisan pasir urug dipadatkan.

\section{METODOLOGI}

Penelitian ini dilakukan dengan metode analisis kuantitatif berupa perhitungan struktur DPT yang dimulai dari pengambilan data tanah lapangan, dilanjutkan dengan simulasi input pembebanan, diteruskan dengan pembuatan model dua dimensi, kemudian dilakukan uji coba kestabilan DPT sampai mendapatkan dimensi yang memenuhi syarat keamanan dan kemudahan dalam pelaksanaan. Perhitungan dilakukan dengan MS Excel 2010 yang dikontrol dengan cara membandingkannya terhadap catatan rekam data pengamatan penurunan bangunan sejenis yang sudah dibangun di sekitarnya setahun sebelumnya. Hasil akhirnya diharapkan memunculkan dimensi DPT yang lebih stabil dan aman terhadap keretakan, guling dan penurunan yang berlebih.

\section{HASIL DAN PEMBAHASAN}

Konstruksi DPT di wilayah Tambak Lorok ini dibuat untuk menahan urugan tanah setinggi 3-5 m pada area yang akan dibangun Gardu Listrik $150 \mathrm{kV}$. Kondisi tanah asli didominasi lempung dan pasir kelanauan sangat lunak-lunak setebal 25-30 meter dengan nilai $\mathrm{N}-\mathrm{SPT}<15$, di bawahnya terdapat lempung dan pasir padat setebal 6-8 meter dengan nilai N-SPT 15-35, kemudian lempung keras sangat kaku setebal 15-20 meter dengan nilai N-SPT 35-45.Sudut geser dalam $\varnothing$ berkisar $1-4^{\circ}$, kohesi 0,90-1,40 t/m2, kadar air $58-69 \%$, berat jenis $1,59-1,62 \mathrm{t} / \mathrm{m} 2$, porositas 61-64\%, koefisien konsolidasi $\mathrm{Cc}=0,69$, permeabilitas $\mathrm{k}=8,45 \times 10^{-9}$ sampai $5,48 \times 10^{-7}$ $\mathrm{cm} /$ det. Tekanan konus sampai kedalaman $5 \mathrm{~m}$ adalah $3-7 \mathrm{~kg} / \mathrm{cm} 2$ dengan hambatan pelekat $896 \mathrm{~kg} / \mathrm{cm}$ ', kedalaman 5-25 m mempunyai tekanan konus $7-15 \mathrm{~kg} / \mathrm{cm} 2$ dengan hambatan pelekat $96-590 \mathrm{~kg} / \mathrm{cm}$ '. Tinggi DPT $5 \mathrm{~m}$ didesain memikul beban hidup merata kendaraan BM 50 menurut SKBI 1987 dan SNI 1725-2016 sebesar 1,1 t/m', melawan tekanan air tanah ke atas (uplift) dengan asumsi muka air tanah sampai puncak DPT,serta menahan tekanan tanah jenuh air dan tekanan air tanah sampai setinggi puncak DPT. Selain itu DPT juga direncanakan meredam gaya gempa sesuai peta Gempa Indonesia 2017 yang menyebutkan wilayah Semarang termasuk wilayah 4 dan tergolong kelas situs $E$ atau tanah lunak yang mempunyai percepatan tanah puncak $(\mathrm{PGA})=$ 0,405 .

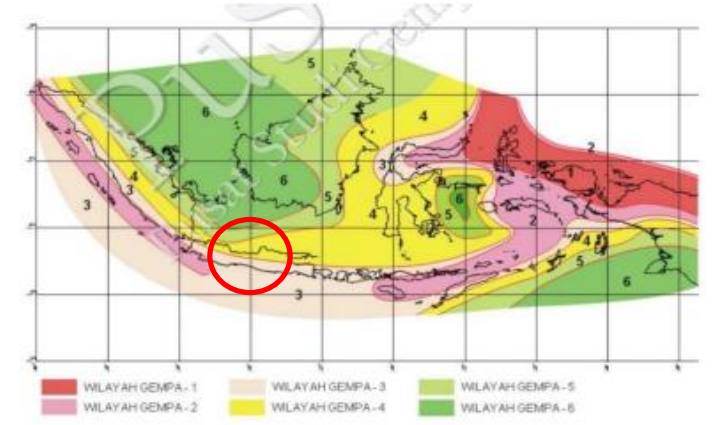

Gambar 1.Peta Gempa Indonesia 2017

Berdasarkan data pembebanan di atas direncanakan dimensi DPT yang cukup stabil dan efektif dilaksanakan di lapangan seperti sketsa terlampir. 


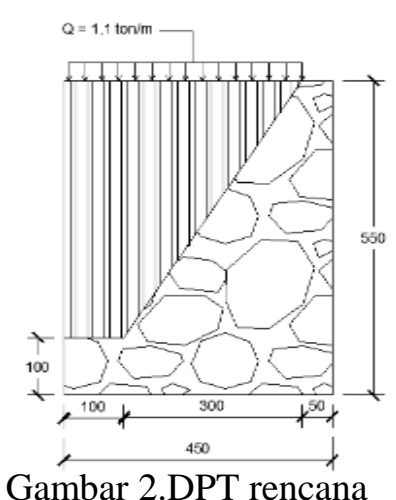

Rangkuman gaya yang bekerja padaDPT dihitung per meter panjang talud dengan hasil sebagai berikut.

\begin{tabular}{|c|c|c|c|c|c|}
\hline No. & $\begin{array}{l}\text { Gaya yang } \\
\text { Timbul }\end{array}$ & Simbol & Hasil & Satuan & Rumus \\
\hline 1 & Gaya Horisontal & $\Sigma \mathrm{ph}$ & 205,40 & $\mathrm{kN}$ & $=\Sigma \mathrm{Pa}-\Sigma \mathrm{Pp}$ \\
\hline 2 & Gaya Vertikal & ¿Pv & 559,24 & $\mathrm{kN}$ & $=\Sigma \mathrm{W}$ \\
\hline 3 & Momen Guling & $\sum \mathrm{PB}_{\mathrm{g}}$ & 402,80 & $\mathrm{kN} \cdot \mathrm{m}$ & $=\Sigma \mathrm{Ma}-\Sigma \mathrm{Mp}$ \\
\hline 4 & Tahanan Guling & $2 \mathrm{Rh}$ & 349,75 & $\mathrm{kN} / \mathrm{m}$ & $=c d \cdot B+W \tan \delta b$ \\
\hline 5 & $\begin{array}{l}\text { Kapasitas daya } \\
\text { dukung }\end{array}$ & $x_{e}$ & 2,01 & $\mathrm{~m}$ & $=\frac{\sum M w-\sum M \alpha}{\sum W}$ \\
\hline 6 & Eksentrisitas & e & $-0,26$ & $\mathrm{~m}$ & $=\frac{\boldsymbol{B}}{\mathbf{2}}-\boldsymbol{X} \boldsymbol{e}<1 / 6 \mathrm{~B}=0,583$ \\
\hline 7 & $\begin{array}{l}\text { Daya Dukung } \\
\text { Ultimit }\end{array}$ & qu & 340,26 & $\mathrm{kN} / \mathrm{m} 2$ & $=i q \cdot C \cdot N c+i y \cdot 0,5 \cdot B^{\prime} \cdot \gamma^{2} \cdot N_{\gamma}$ \\
\hline 8 & $\begin{array}{l}\text { Daya Dukung } \\
\text { Ultimit merata }\end{array}$ & $q^{\prime}$ & 111,61 & $\mathrm{kN} / \mathrm{m}$ & $-\frac{\sum V}{B^{V}}$ \\
\hline 9 & & iq & 0,974 & - & $-\left[1-\left[\frac{0,5 \sum H}{\sum V+A \times C_{2} \times \tan \phi}\right]\right]$ \\
\hline 10 & $\begin{array}{l}\text { Faktor } \\
\text { Kemiringan }\end{array}$ & ic & 1,000 & - & $=\bar{i} \varepsilon-\left[\frac{1-i \bar{q}}{N q-1}\right]$ \\
\hline 11 & & iy & 0,394 & - & $=\left[1-\left[\frac{0,7 \sum H}{\Sigma V+P \times C_{2} \times \cos \operatorname{lan} \phi}\right]\right]^{3}$ \\
\hline
\end{tabular}

Gambar3.Gaya yang bekerja dan daya dukung batas

Selanjutnya kestabilan DPT per meter panjang talud dianalisis pada kondisi paling ekstrim yaitu muka air tanah setinggi puncak talud, terjadi gempa, gaya angkat berfungsi $100 \%$, pada permukaan talud terdapat kendaraan bertekanan gandar terpusat 5 ton sedang berhenti sedangkan tahanan tanah pasif tidak diperhitungkan. Besarnya gaya dalam baik tarik, tekan dan geser pada pasangan batu terutama pada bagian kaki talud, akan dicek supaya tidak melebihi batas ijin dan menghindari terjadinya keretakan yang berpotensi menimbulkan guling dan penurunan tidak seragam antar pias DPT. Penurunan segera dan konsolidasi dijumlah total untuk diprediksi seberapa besar DPT turun dan terjadi pada tahun ke berapa sejak talud difungsikan. Penggunaan tiang pancang kayu atau dolken dimaksudkan sebagai struktur bawah tambahan untuk memperkecil besaran penurunan dan mengkondisikan terjadinya penurunan DPT secara seragam. Daya dukung kelompok tiang dolken memperhitungkan efisiensi kemampuan dukungnya dengan hanya mengandalkan tahanan ujung dan mengabaikan tahanan geser karena lapisan tanah lunak yang cukup tebal 25-30 meter. Panjang tiang dolken dibatasi 4 meter sesuai yang tersedia di lapangan dengan diameter minimal $12 \mathrm{~cm}$.

Tabel 1. Hasil analisis FK DPT

\begin{tabular}{|c|l|c|c|c|}
\hline No & Uraian & Analisis & Ijin & Status \\
\hline 1 & $\begin{array}{l}\text { FK Daya } \\
\text { dukung }\end{array}$ & 3,05 & 3,00 & Ok \\
\hline 2 & $\begin{array}{l}\text { FK Gaya } \\
\text { angkat }\end{array}$ & 2,26 & 2,00 & Ok \\
\hline 3 & FK Geser & 1,70 & 1,50 & Ok \\
\hline 4 & $\begin{array}{l}\text { FK } \\
\text { Guling }\end{array}$ & 3,78 & 2,00 & Ok \\
\hline 5 & $\begin{array}{l}\text { Eksentri- } \\
\text { sitas (cm) }\end{array}$ & 24 & 58 & Ok \\
\hline 6 & $\begin{array}{l}\text { Teg.tekan } \\
\left.\text { (kg/cm }{ }^{2}\right)\end{array}$ & 225,52 & 1500 & Ok \\
\hline 7 & $\begin{array}{l}\text { Teg.tarik } \\
\left.\text { (kg/cm }{ }^{2}\right)\end{array}$ & 94,04 & 300 & Ok \\
\hline 8 & $\begin{array}{l}\text { Teg.geser } \\
\left.\text { (kg/cm }{ }^{2}\right)\end{array}$ & 39,12 & 150 & Ok \\
\hline 9 & Si (cm) & 2,17 & - & - \\
\hline 10 & Sc (cm) & 30,01 & & - \\
\hline 11 & $\begin{array}{l}\text { Stot-fak. } \\
\text { koreksi } \\
0,80(\mathrm{~cm})\end{array}$ & 25,74 & - & - \\
\hline 12 & $\begin{array}{l}\text { Est. Stot } \\
\text { (tahun) }\end{array}$ & 13 & - & - \\
\hline 13 & $\begin{array}{l}\text { Daya } \\
\text { dukung 1 } \\
\text { dolken } \\
\text { (kg) }\end{array}$ & 339,12 & - & - \\
\hline
\end{tabular}

Dari tabel di atas terlihat prediksi penurunan yang terjadi cukup besar yaitu $25,74 \mathrm{~cm}$ yang akan dicapai setelah 13 tahun DPT difungsikan. Untuk mengurangi hal ini, bagian dasar talud dapat dipasang pasir urug dipadatkan setebal $10 \mathrm{~cm}$ dan lantai kerja beton tumbuk minimal $10 \mathrm{~cm}$ agar permukaan pondasi DPT merata sehingga dapat membantu menyebarkan beban secara seimbang ke seluruh permukaan tanah asli. 
Penurunan cukup besar ini terjadi karena kondisi tanah asli yang jenuh air sepanjang waktu akibat intrusi air laut. Cara lain untuk meminimalkan penurunan adalah memasang polypropelene vertical drainage (PVD) yaitu semacam serat sintetik yang dipasang sedalam lapisan tanah lunak pada setiap jarak 1 meter. Pemasangan PVD akan memompa air tanah naik ke permukaan secara kapiler sehingga tanah urug dipercepat pemampatannya. Tanah yang lebih padat akan berkurang kadar porinya sehingga tidak mudah disusupi air dan memiliki ikatan antar butiran yang lebih bagus, tidak mudah terurai, tidak mudah kembang susut yang menyebabkan terjadinya penurunan. Pemasangan PVD dilakukan segera setelah tanah urug dihamparkan dan proses kapilerisasi air tanah ini berlangsung 612 bulan, baru setelah itu DPT dibangun.

\section{KESIMPULAN}

Hasil analisis memperlihatkan bahwa DPT masih stabil berdiri di atas timbunan tanah lunak dan memenuhi syarat faktor keamanan struktur baik terhadap daya dukung tanah, efek uplift, geser, guling, keretakan konstruksi akibat gaya dalam yang berupa tekan, tarik maupun geser. Penurunan yang terjadi dapat diatasi dengan menambah tiang pancang kayu berdiameter minimal $12 \mathrm{~cm}$ pada jarak setiap 1 meter sedalam 4 meter. Tiang dolken yang digunakan harus tahan asam basa sulfat, lurus, tidak bermata kayu dan anti rayap. Sebelum DPT dibangun, tanah urug dimampatkan dengan PVD selama 6-12 bulan agar tanah lebih padat untuk mengurangi besaran penurunan. Konstruksi pasangan batu harus menggunakan batu kali belah, semen jenis II atau V (tahan sulfat, asam dan panas hidrasi sedang-tinggi) sesuai SNI 15-2049-2004 tentang Semen Portland, pasir setara pasir Muntilan dengan kadar lumpur maksimum 5\% dan air yang tidak mengandung minyak, garam, sulfat, alkali, bersifat asam sesuai standar air bersih yang berlaku.Spesi yang digunakan merupakan campuran kedap air 1PC:3Ps.

\section{DAFTAR PUSTAKA}

Bouwless, 1993, Analisa dan Desain Pondasi I, Erlangga, Jakarta
Ditjen SDA, 2002, RPT0-Pd-T Spesifikasi Teknik Pekerjaan Pasangan Batu, Departemen PU, Jakarta

Laboratorium Mekanika Tanah, Fakultas Teknik Undip, 2017, Laporan Penyelidikan Tanah Proyek Pembangunan Tambak Lorok Semarang

Hardiyatmo, Hary Christady, 2014, Analisis dan Perancangan Fondasi I, Gadjah Mada University Press, Yogyakarta

Indriani, Satyanta P, Dewi S, 2012, Analisis Sebaran Genangan Pasang Air Laut (Rob) Berdasarkan High Water Level dan Dampaknya pada Penggunaan Lahan di Kecamatan Semarang Utara, Journal Geo Image Unnes, Semarang

Ludiro, HW, 2011, Studi Penurunan Tanah Kawasan Pelabuhan Tanjung Emas Semarang, e-Journal Wahana, Polines, Semarang

Pusat Studi Bencana LPPM Undip, 2017, Laporan Final Kajian Teknis Mitigasi Banjir Rob di GI Tambaklorok, PLN Enjineering, Jakarta

SKBI 1.3.28, 1987, Pedoman Perencanaan Pembebanan Jembatan Jalan Raya, Yayasan BPPU, Jakarta

SNI 03-1727-1989, Pedoman Perencanaan Pembebanan untuk Rumah dan Gedung, BSN, Jakarta

SNI 2836-2008, Perhitungan Harga Satuan Pekerjaan Pondasi Batu Belah, BSN, Jakarta

SNI 1725-2016, Pembebanan untuk Jembatan Jalan Raya, BSN, Jakarta

SNI 8640-2017, Persyaratan Perancangan Geoteknik, BSN, Jakarta

Sosrodarsono, Suyono, Nakazawa, Mekanika Tanah dan Pondasi, Pradnya Paramita, 1984

Suhartono, Purwanto, Suripin, 2013, Kondisi Intrusi Air Laut terhadap Air Tanah pada Akuifer Kota Semarang, Prosiding Seminar Nasional Pengelolaan Sumber Daya Alam dan Lingkungan, LPPM Undip, Semarang

Widayat, 2015, Rekayasa Pondasi I, Teknik Sipil UNPAND, Semarang

Yoga A, Dhimas Noor, Indrastono, Himawan, 2013, Evaluasi Geoteknik dan Struktur pada Dermaga Eksisting TPK Semarang, PT Pelindo III, Surabaya. 